\title{
DAY LABOURERS IN PRETORIA - ENTREPRENEURIAL SPIRIT IN ACTION OR SURVIVORS IN A CUL DE SAC?
}

\author{
P F BLAAUW \\ Department of Economics \\ University of Johannesburg \\ pfblaauw@uj.ac.za \\ A M PRETORIUS \\ Department of Economics \\ University of South Africa \\ pretoami@unisa.ac.za
}

\begin{abstract}
Many of the unemployed in South Africa have to venture into the informal sector to raise income. The aim of this article is to describe the demographic and economic features of day labourers in Pretoria and to determine whether their activity in the informal sector is an exercise in entrepreneurship or a desperate effort to survive. The day labourers were found to be mainly male, young, very low skilled, experiencing no income security and supporting on average four people. The article concludes that day labourers are not guided by a spirit of entrepreneurship and are therefore not involved in this activity by choice in spite of other options.
\end{abstract}

Key Words

Entrepreneurship, casual labour, informal economy

\begin{abstract}
Many of the unemployed in South Africa have no other choice but to venture into the informal sector of the economy to raise income or else accept that they will have to be dependent on other income earners for survival (Whiteford \& Van Seventer, 1999). Defining the informal sector is a difficult proposition. It is widely acknowledged that the sector includes all unregistered and unrecorded economic activities that normally escape detection in the official estimates of GDP (Ligthelm, 2006). This provides the basis for Barker's definition: "Unorganised, unregulated and mostly legal but unregistered economic activities that are individually or family owned and use simple, labour intensive technology" (Barker, 2007, p. xvii). Statistics South Africa defines informal sector employment as: "...unregistered business, run from homes, street pavements or other informal arrangements" (Statistics South Africa, 2003, p. xiii). People working in the informal sector may be self employed, or employees (Muller, 2003). Since 2000 respondents in the October Household and Labour Force Surveys were asked whether they engaged in any one of a number of specific, mostly low income activities. These included "guarding cars" or "making things for sale".
\end{abstract}

Day labouring can therefore be defined as a casual job seeking activity where workers wait on street corners or in other public places looking for work. They are individuals who work for different employers and get paid on a daily basis. Being excluded form the formal labour market these workers often work for different employers each day, are paid in cash and do not enjoy benefits like health insurance and unemployment benefits. The employers, however, mainly benefit from this relationship. They do not have many commitments towards these workers and can use them only when work is available (Blaauw, Pretorius, Louw, \& Schenck, 2006).

Informal employment in South Africa, as well as in the rest of the world, comprises diverse activities. Some activities, for example car guarding, are merely survivalist in nature, yielding relatively low income. In 2001 the average daily income of car guarding in Bloemfontein was $\mathrm{R}$ 32-00 for people not belonging to a car guard organisation and R 52-40 for those who did (Blaauw \& Bothma, 2003). In general, average informal earnings decreased dramatically from 1995 and 2000, but have been stable since (Burger \& Yu, 2006). Other activities have the potential to yield very high returns. In some cases these returns might even be higher than the average earnings from normal formal sector employment.

In South Africa there are thousands of people, standing at the side of the road, waiting for informal and in most cases temporary employment. The research problem that beckons is whether the day labourers who are involved in this activity are involved by choice, guided by a spirit of entrepreneurship or formally unemployed people without any hope or any future who are trapped in an informal labour market merely in an effort to survive?

\section{Aim of the research}

Against this background, the objective of this study is to:

1. determine what the demographic and economic features of day labourers in Pretoria are;

2. determine whether their presence in this part of the informal sector is voluntary, guided by an entrepreneurial spirit or a last resort for income generation.

To achieve the above objectives, data are required on the origin of these people, their demographic characteristics, whether formal sector employment was once held, for how long it was held and the reasons for losing/leaving it. The income generated from this activity will be compared with accepted proxies for the minimum income needed to survive materially.

In order for day labouring to be regarded as an entrepreneurial exercise, key elements from the multitude of definitions of entrepreneurship must be present in their actions. Entrepreneurship today is a complex phenomenon involving multiple stake-holders, an array of inputs that can be combined in innumerable ways, significant adaptation of these inputs and combinations over time, a variety of obstacles and constraints, and high levels of uncertainty regarding outcomes (Kuratko, 2006). Van Aardt \& Van Aardt (1997) defined entrepreneurship as the act of initiating, creating, building and expanding an enterprise or organisation, building an entrepreneurial team and gathering other resources to exploit an opportunity in the market place for long term gain. The following characteristics of an entrepreneur are identified by Van Aardt \& Van Aardt (1997): a desire to achieve, hard workers, nurturing quality, accepting responsibility, reward-oriented, optimistic, excellence oriented, good organisers and money-oriented. Earlier studies regarding entrepreneurship in Africa showed that typical 
African entrepreneurs were mainly male, middle-aged, married with children and well educated (Kiggundu, 2002). Kuznetsov, McDonald \& Kuznetsova (2000) identified the following competencies present in entrepreneurs: opportunity alertness; the ability to be innovative; industryrelated experience; participation in important networks and sharing common values with important actors in the market; personal knowledge of business partners; and the ability to mobilize intangible assets.

The accepted definition of entrepreneurship for the purpose of this article is "...the process whereby an individual or groups of individuals use organized efforts to pursue opportunities to create value and grow by fulfilling wants or needs through innovation and uniqueness, no matter what resources the entrepreneur currently has" (Coulter, 2003, p. 6).

The rest of the article will be structured as follows: First the results of the appropriate literature study and an exposition of the research methodology employed are presented. The results of the survey done among day labourers in Pretoria in 2004 are then presented and analysed and conclusions regarding the problem statement drawn.

\section{Literature study}

The consensus in the South African literature (Hofmeyr, 1998; Braude, 2005) is that employment in the informal sector offers a second best alternative to formal sector employment. Africans in the majority of cases, who are unable to secure employment in the formal sector, are forced to resort to informal means of employment in order to subsist in one of a range of low-income, marginal informal sector activities (Bhorat, Leibbrandt, Maziya, van der Berg \& Woolard, 2001; Muller, 2003).

Informal employment in South Africa, as well as in the rest of the world, comprises diverse activities. These include street vending, gardening, bricklaying, painting, sewing, driving, caring, operating a shop or spaza, hairdressing, welding, managing, and practicing traditional medicine. This underlines the heterogeneous nature of the informal economy (Devey, Skinner \& Valodia, 2003). The increasing informalisation of employment is responsible for the fact that a significant portion of the workforce is unable to access the formal institutions that govern the labour market as well as retirement provisions and medical insurance, which form part of remuneration in the formal sector of the economy (Valodia, Lebani, Skinner \& Devey, 2006).

Literature on day labourers in South Africa is limited mainly to the occasional article in the daily press. A study by Schenck and Louw (2005) in the vicinity of the suburb of Elardus Park in Pretoria (Tshwane) indicated that men interviewed work long hours and waits almost every day for employment in harsh climatic conditions. They have to be content with an average daily wage of between fifty and sixty rand for a long day's work. They are willing to do anything, from gardening to the mixing of cement, painting, or the loading and unloading of heavy goods. They are prepared to do this kind of work because it is their only means of earning an income. Many days go by without many of these men obtaining any work at all. This study laid an important foundation for a more thorough study, encompassing the whole of Pretoria (Tshwane).

Gonzo and Plattner (2003) did a study among day labourers in Windhoek, Namibia. Their results showed a marked similarity with the study of Schenck and Louw (2005) in terms of working conditions, educational qualifications and income earned.

The next section contains a detailed description of the research methodology used in doing the field work for the research.

\section{RESEARCH DESIGN}

Research approach

In response to the work done by Schenck and Louw (2005), several consultative meetings were held by the members of their research team at the University of South Africa during the first part of 2004. This laid the foundation for the formulation of the questionnaire for a thorough follow-up study.

\section{Respondents}

Before the actual survey was conducted a detailed reconnaissance of the greater Pretoria area were done to determine the size of the research population. The estimated number of day labourers in Tshwane is between 2000 and 2500 . It must be noted that the number varies on a daily basis.

The sample population that was earmarked for investigation was scientifically determined using the above information. To compile a stratified sample the research population must be allocated proportionally between the various hiring sites in terms of the size of the sites. The various hiring sites were therefore classified according to the number of workers standing at each site. Table 1 presents the classification of the sites according to size and site number.

TABLE 1

Classification of hIRING SITES ACCORDING To SIZE AND SITE NUMBER

\begin{tabular}{|c|c|c|}
\hline Size of site & Site number & \\
\hline Small sites: & 1 - 25 people & $\begin{array}{l}1,2,3,5,6,8,9,11,18,19,21, \\
22,24,25,27,28,29,30,31,32, \\
33,34,36,38,40,42,49,53,55 \\
56,57,58,59,61,65,66,69\end{array}$ \\
\hline
\end{tabular}

Medium sites:

Small-medium sites: $\quad 26-35$ people $2-7,12,13,17,20,23,26,41,47$,

Large-medium sites: 36 - 50 people $\quad 4,16,48,50,51,54,60,62,63$, 64,67

Large sites: $\quad 51-100$ people $\quad 10,14,15,35,37,39,43,45,70$

Mega sites: $\quad 100+$ people $\quad 44,46$

Source: Survey dat

A representative sample of two hundred and forty workers was proportionately selected for interviewing.

\section{Measuring instrument}

The survey took the form of structured interviews. This method ensures that questions are not misunderstood or misinterpreted (Bless \& Higson-Smith, 1995). The questionnaire for the survey was designed using the methodology followed in similar studies in the United States by Valenzuela Jr, Theodore, Meléndez \& Gonzalez (2006) as well as inputs of the researchers from the University of South Africa who did the earlier preliminary research mentioned above (Schenck \& Louw, 2005). A questionnaire consisting of four sections was used. The first three sections contained questions pertaining to the demographic features and working conditions of day labourers. The last section included questions regarding the possible abuse of this vulnerable group in the economy.

\section{Procedure}

The next step was to recruit suitable fieldworkers and provide them with appropriate training. Twenty fieldworkers were hired. They were all third-year and postgraduate students from the Department of Social Work at the University of South Africa. These fieldworkers were chosen to be able to communicate with respondents in English and at least another African language. Two days were used to train 
the fieldworkers to be proficient with the questionnaire. This was followed up by a trail run of interviews. The completed questionnaires were evaluated in order to identify possible ambiguous questions. The final questionnaire was adjusted to eliminate ambiguities and respond to the comments received from fieldworkers.

The fieldworkers conducted the fieldwork in a period of four days from the 27th to the 30th of September 2004. Fieldwork began at 06:00 in the morning. The cooperation received from the respondents was very positive overall. The personal nature of the interviews meant that the questions were thoroughly explained to the respondents. During the interviews a total of 242 questionnaires (about 10 per cent of the research population) were satisfactorily completed for the sample population.

\section{RESULTS}

The demographics and working conditions of day labourers in Pretoria

As was expected, the day labourers in Tshwane were almost exclusively male. The gender distribution is 97,5 per cent male and 2,5 per cent females respectively. Of the two hundred and forty-two respondents, 88 per cent were born in South Africa. The remaining respondents were born in Zimbabwe ( 7 per cent) and Mozambique (2,9 per cent). Five respondents, 2,1 per cent, did not want to specify the country of their birth. It is surmised that these men were also born outside the borders of South Africa (Blaauw, Louw \& Schenck, 2006: 462. This corresponds with research on international migrants in South Africa which shows that these people are very active in the informal economy (Valodia et al., 2006). Although foreign migrants are entering the informal economy they remain marginalised and unable to make the transition into the formal economy. The opposite occurs in the United States (Valenzuela Jr. et al., 2006).

A very interesting statistic is the fact that as many as two hundred and fifteen or 88.8 per cent of the day labourers interviewed came from outside Gauteng in order to seek employment in Tshwane. Almost sixty per cent of the day labourers came from Limpopo and Mpumalanga (Blaauw et al, 2006: 462).

Almost three quarters of the respondents in the survey are under thirty-five years old. In fact, 61,2 per cent of the day labourers involved in the survey is under thirty years old. A hundred and thirty-six (56,2 per cent) of the respondents indicated that they had never been married. Thirty-three per cent are married, under either common law or customary marriage. Fifteen (or 6,2 per cent) of the day labourers are living with a partner and 3,7 per cent are separated or divorced.

Day labourers involved in this survey have on average one or two children. The majority (33,6 per cent) maintain that they have no children and 22,8 and 19,9 per cent maintain that they have one and two children respectively. One respondent indicated that he has more than ten children.

On average, each day labourer supports 4 people (including himself) from the income earned in this informal labour market. More than half of the respondents (56,2 per cent) support up to four people. Of the respondents, 4,1 per cent indicated that they support more than 9 people from their income. By using the frequency results of the questionnaire, it was estimated that the informal labour market of day labourers provides some income for at least ten thousand people (Blaauw et al, 2006: 462).

Day labourers interviewed in this survey displayed disappointing levels of formal schooling. Figure 1 represents the educational qualifications obtained by the sample population.

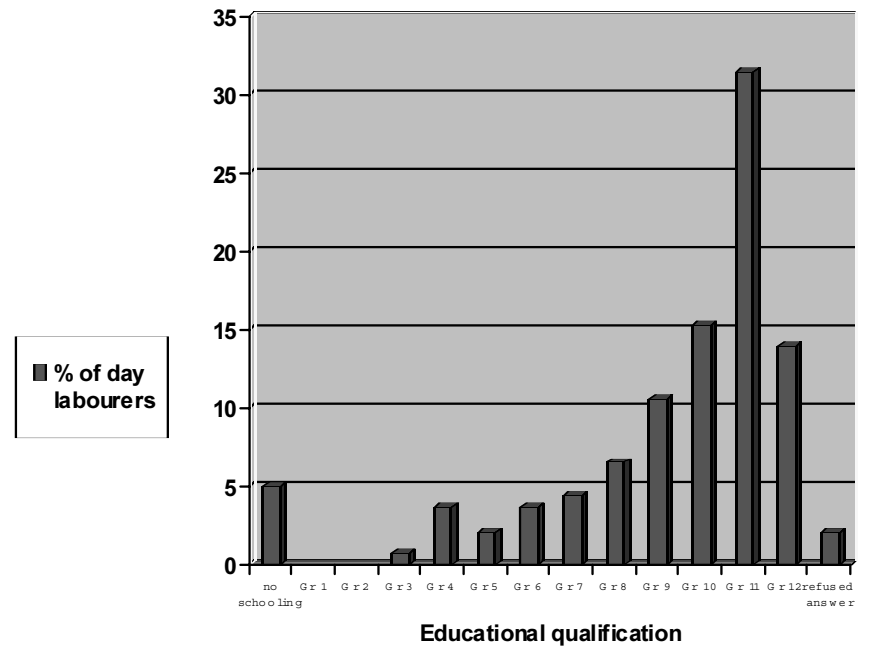

Source: Survey data

Figure 1: The educational profile of day labourers in Pretoria

An evaluation of the working conditions of this informal labour market provides prima facie evidence for answering the second objective of the paper. The survivalist nature of this informal labour market is clearly illustrated by the fact that 51,2 per cent of the sample population stand and wait for work between five and six days per week. Forty-eight respondents $(19,8$ per cent) indicated that on all seven days of the week they stood waiting at a site in the hope of finding employment.

In summary, the day labourers involved in this study were found to be mainly male, fairly young, having relatively low levels of schooling, experiencing no certainty in terms of income security, supporting on average four people and working under harsh conditions. These trends correspond with the findings of other research on the informal economy (Valodia et al., 2006)

The employment history of day labourers in Pretoria A hundred and two of the respondents maintain that they did in fact have permanent employment in the formal sector of the economy before becoming day labourers. This represents a significant 42,1 per cent of the sample. Five workers did not answer that particular question, leaving a hundred and thirtyfive (55,8 per cent) who did not have previous formal employment (Blaauw et al, 2006: 464).

Figure 2 highlights the period for which these people were previously employed in the formal sector of the economy.

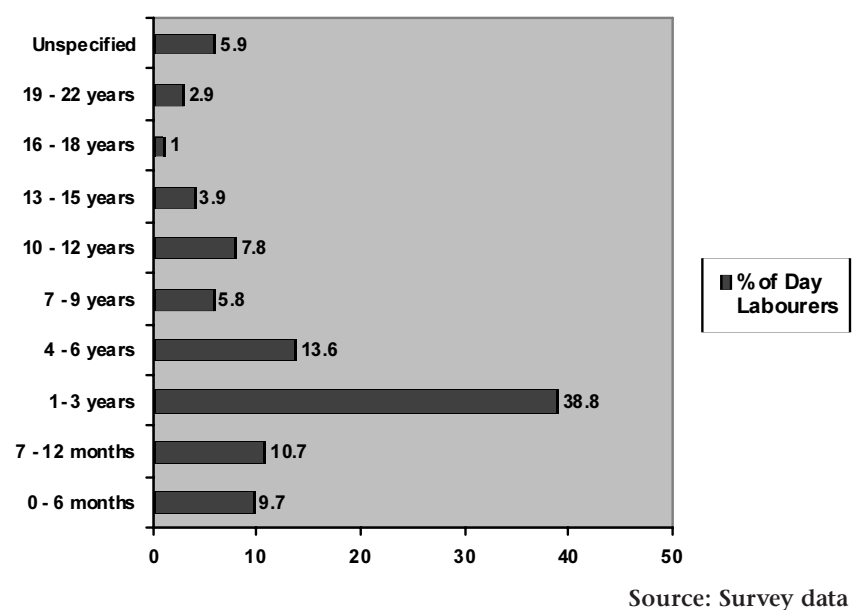

Figure 2: Periods for which day labourers were employed in the formal sector 
Of the respondents who did have previous employment, 59,2 per cent had worked in such employment for a period of three years and less. 21,4 per cent held employment for longer than 10 years. Three workers held positions in the formal sector for longer than nineteen years (Blaauw et al, 2006: 466).

Respondents were asked to state their reasons for leaving their previous employer. Layoffs in the form of retrenchments and the closure of businesses were responsible for 71,9 per cent of the flow out of the formal sector of the economy. This follows the trend as observed in the informal labour market of car guards in Bloemfontein (Blaauw \& Bothma, 2003). Two of the 102 refused to answer this question. More than twenty per cent of the respondents quit their full-time employment for reasons such as a wage that was considered to be too low and health reasons.

\section{DISCUSSION}

In general the skills level of the day labourers are very low. This makes it difficult for them to obtain alternative employment opportunities in the formal sector of the economy, since the demand for low-skilled labour in South Africa is continuously declining (Loots, 1998).

A working week of six and sometimes seven days per week puts a big strain on the social fabric of the community where these people live. The limited time available for relaxation and family life does not augur well for the quality of life of the people involved in this activity. This is, however, the harsh reality of these people's lives. For most of them this is the only alternative available in a labour market that requires a lot more human capital than they can offer. These circumstances make it difficult to say with any conviction that day labourers in Pretoria are involved in this activity as a matter of choice.

It is evident that many of the respondents held stable employment for a relatively long period of time. For their current activity to be classified as a manifestation of a spirit of entrepreneurship, this should be reflected by their reasons for leaving stable employment. However, an investigation showed that layoffs in the form of retrenchments and the closure of businesses were responsible for more than 70 per cent of the current day labourers' leaving their formal employment. More than twenty per cent of the respondents quit their full-time employment for reasons such as a wage that was considered to be too low and health reasons. It cannot be assumed that this indicates a desire to be self-employed, guided by a spirit of entrepreneurship.

The vast majority $(90,1$ per cent) of the respondents indicated that they would accept full-time formal sector employment if it was available. In contrast, Lighthelm (2004) found that on average 58,1 per cent of the respondents in his survey among informal hawkers in Tshwane indicated that they would not accept a salaried job if it were offered to them. This comparison clearly indicates that it is unlikely that day labourers see themselves as self-employed entrepreneurs who "...feel good about themselves, about their work lives, and about the economic rewards they earn" (Timmons, 1994, p. 3).

Analysing the income of the day labourers will provide further evidence to determine whether these people can be regarded as entrepreneurs or whether they are stuck in this activity because they have no alternative means of survival.

Table 2 provides an analysis of the possible link between the levels of schooling and earnings.
TABLE 2

Ppossible Link BetWeen THE LeVel OF SCHOOLING OF DAY LABOURERS IN PRETORIA AND INCOME IN 2004

\begin{tabular}{ll}
\hline Variables & Correlation Coefficient \\
\hline $\begin{array}{l}\text { Expected/Desired level of income } \\
\text { \& level of schooling: }\end{array}$ & $\begin{array}{l}0,054 \text { (only statistically significant at } \\
\text { levels of } 20 \% \text { and more) }\end{array}$ \\
$\begin{array}{ll}\text { Actual income earned in previous } \\
\text { month \& level of schooling: }\end{array}$ & $\begin{array}{l}0,093 \text { (only statistically significant at } \\
\text { levels of } 20 \% \text { and more) }\end{array}$ \\
\hline
\end{tabular}

Source: Survey data

From table 2 it is clear that there is no real link between the level of schooling and expected earnings. An investigation into the link between the level of schooling and the income earned did, however, indicate a tendency for earnings to increase with an increased level of schooling. The correlation between the actual income earned in the previous month and the level of schooling of the respondents is markedly higher, namely 0,093. These correlation coefficients however only become statistically significant at levels of $20 \%$ and more.

From the data it is also clear that other forms of formal and informal training have no real influence on the income obtained by the day labourers. Those with training in painting earned on average R612,7; those with electrical training R675; those with training in plumbing R1300; training in carpeting R698; welding training R397,5 and security training an amount of R700.

The most pertinent answer to the research question lies in the comparison between the income earned by day labourers and the minimum level of income necessary for subsistence in South Africa.

More than half or 57,6 per cent of the respondents earned less than R700 in the month preceding the survey. An even more significant statistic is the fact that 24,7 per cent of the day labourers received an income of less than R300 per month. This is 15,2 per cent lower than the national poverty line of R354 per month per adult in 2002 (United Nations Development Programme, 2003, p.6). Given the impact of inflation, this section of the sample population is living in absolute poverty unless they have other sources of income or support. They cannot even sustain themselves, let alone the average of four people that depend on their income. On average, the monthly income in a typical month of activity fluctuates between a minimum of no income in the worst case scenario and a maximum of R4500. The overall average income earned in the previous month was R672,17.

The above and other possible estimates of the average monthly income of day labourers were compared with the minimum living level of monthly income in South Africa. The results are summarised in table 3 below.

TABle 3

AVERAGE MONTHLY INCOME OF DAY LABOURERS COMPARED WITH THE Minimum Living LeVel of Monthiy income in Pretoria IN 2004

Average monthly income of day labourers in a good month* R 1187,46

Average monthly income of day labourers in a bad month* R 401,93 Average monthly income of day labourers in August 2004* R 672,17 Monthly minimum living level per size of household in Pretoria\#

$\begin{array}{ll}\text { 2 people } & \text { R } 1060,29 \\ \text { 3 people } & \text { R } 1398,57 \\ 4 \text { people } & \text { R } 1728,10 \\ 5 \text { people } & \text { R } 2052,73 \\ 6 \text { people } & \text { R } 2401,02 \\ & \text { R } 2007,36\end{array}$

Average family in an African household R 2007,36 
The estimates of Martins (2004), quoted in table 3, paint a very sombre picture. His estimates are important as it was established that the average day labourer supports four people on his income. Even if it is assumed that all of them reside within the same dwelling, it is clear that day labourers are not even able to support these dependents in months that can be classified as good in terms of income earning possibilities, let alone in an average or bad month. In an average month they only earn 39 per cent of the minimum amount needed to support a household of four people (Blaauw et al, 2006: 469).

These findings correspond to other studies on informal sector activities in the Pretoria region. Ligthelm (2004) determined that the average monthly turnover and gross profit for informal market activity in Tshwane (Pretoria) was R3420 and R1010 per month respectively. This is only half the amount required to sustain the average African household in Pretoria (Martins, 2004).

The above data prove beyond all reasonable doubt that being a day labourer can provide a means of survival, but on average the income earned is not adequate to support a family and other dependants. This does not support the suggestion by Timmons (1994) that entrepreneurs are working towards a better life for themselves and their families (Blaauw et al, 2006: 469).

Day labourers involved in this study were mainly male, fairly young, generally low skilled, earning low and uncertain levels of income and working under harsh conditions. The occurrence of social problems threatening the social fabric of these communities is a reality (Blaauw et al, 2006: 469).

The second objective of the paper was to determine whether day labourers in Pretoria should be regarded as people guide by a spirit of entrepreneurship or people stuck in this activity as a last resort in order to survive.

Many of the respondents held stable employment for a relatively long period of time. For their current activity to be classified as a manifestation of a spirit of entrepreneurship, this should be reflected by their reasons for leaving stable employment. Layoffs and people quitting or resigning were cited, by respondents who had held formal sector employment, as the main reasons for losing their jobs. This indicates that the vast majority of these people did not leave their full-time employment because they were prompted to do so by the spirit of entrepreneurship. Very few of the required characteristics stemming from the definition of entrepreneurship were reflected by the available data. More than half of the day labourers in Pretoria are standing on the side of the road for 5 to 6 days every week. The study by Schenck \& Louw (2005) confirms that these men work for long hours when they do find casual employment. They therefore do meet one of the entrepreneurial characteristics identified by Van Aardt \& Van Aardt (1997), namely hard work. Other characteristics for example being optimistic are not evident here.

In their study on the relationship between entrepreneurial attitude orientations and different biographic/demographic, personality and work related variables (Van Wyk, Boshoff \& Bester, 2006) found strong relationships between entrepreneurial attitudes and personality and work variables. The work variables included job satisfaction and job involvement. This strong sense of job satisfaction is not evident in the day labourers in Pretoria. The vast majority of the respondents that said they would like to return to formal sector employment bore testimony to this.

Scholars like Gartner (1988) regard entrepreneurship strictly as the creation of organisations. What differentiates entrepreneurs from non-entrepreneurs is that entrepreneurs create organisations, while non entrepreneurs do not (Gartner, 1988). If this definition is applied then day labourers in Pretoria per definition do not meet the requirements stemming from the above definition.

Analysing the income of the day labourers provided further evidence that day labourers are stuck in this activity as a matter of survival because they do not have any alternative. On average a day labourer is barely able to support himself in months which can be classified as bad in terms of income earned. It is doubtful whether day labourers are able to support their dependants in months that can be classified as good in terms of income earning possibilities. Being a day labourer can provide a means of survival, but the income earned on average is not adequate to support a family and other dependants. This is not consistent with the argument that these are entrepreneurs involved in an activity although other options are available. These findings correspond with other studies (Martins, 2004; Ligthelm, 2006) on informal sector activities in the Pretoria region.

Unfortunately it is clear that as in the case of several other informal sector activities day labourers are not entrepreneurs who are self employed by choice. They are like their counterparts in many other informal sector activities, stuck in a cul de sac in the form of an activity that they have to pursue in order to survive. Day labouring is a last resort; the day labourers have no hope of achieving an improvement in their quality of life in the form of formal sector employment that offers them a decent income.

\section{Limitations of the research}

One of the limitations of the research is the fact that this case study covers only one city and one needs to be careful to draw inferences on the research question for the whole of South Africa from the available data. It is therefore important to extend this type of analysis to a country wide study as suggested in the next section.

It must always be kept in mind that the fluent nature of this employment seeking activity ensures that the picture in terms of the various hiring sites and the number of workers standing at each, changes constantly. The research therefore represents a snapshot of the current situation and can be repeated to provide a better understanding of the evolvement of this activity over time.

\section{RECOMMENDATIONS FOR FURTHER RESEARCH}

Further research for this topic is recommended, as this case study among day labourers was limited to the Pretoria region. It is recommended that the same study be conducted on a country wide scale, covering at least all the metropolitan areas in the nine provinces as well as the most important rural hubs in each. Possible differences in the demographic and economic characteristics between provinces will be brought to the fore in this process.

The research must be repeated for the Pretoria region as part of a country wide study. This will improve the better understanding of the evolvement of this activity over time.

This process will further serve to test the validity of the above findings and provide additional credible primary data in terms of the living conditions, income earned and migration patterns of this informal sector activity in South Africa. It will also make international comparisons possible given the body of research done among day labourers in Namibia and the United States for example. 


\section{REFERENCES}

Barker, F. (2007). The South African Labour Market, 5th edition. Pretoria: Van Schaik.

Bhorat, H., Leibbrandt, M., Maziya, M., van der Berg, S. \& Woolard, I. (2001). Fighting poverty - labour markets and inequality in South Africa. Cape Town: UCT Press.

Blaauw, P.F. \& Bothma, L.J. (2003). Informal Labour Markets as a solution for unemployment in South Africa - a case study of car guards in Bloemfontein. South African Journal of Human Resource Management, 1 (2), 40 - 44.

Blaauw, P.F., Louw, H. \& Schenck, C.J. (2006). "The employment history of day labourers in South Africa and the income they earn - A case study of day labourers in Pretoria." South African Journal of Economic and Management Sciences, NS 9 (4), 458 - 471.

Blaauw, P.F., Pretorius, A.M., Louw, H. \& Schenck, C.J. (2006). "The socio economic reality of being a day labourer in South Africa." Department of Economics Research Paper no. 0605, University of Johannesburg, p. 1 -11, ISBN: 0-86970-649-7.

Bless, C. \& Higson-Smith, C. (1995). Fundamentals of Social Research Methods - an African Perspective, 2nd edition. Cape Town: Juta.

Braude, W. (2005). South Africa: bringing informal workers into the regulated sphere, overcoming Apartheids' legacy, in Good jobs, bad jobs, no jobs - labor markets and informal work in Egypt, El Salvador, India, Russia, and South Africa under editorship of Avirgan, T., Bivens, L. J. \& Gammage, S. Washington D.C.: Economic Policy Institute.

Burger, R. \& Yu, D. (2006). Wage trends in post-apartheid South Africa: constructing an earnings series from household survey data. South African Reserve Bank: Labour Market Frontiers nr 8, 1 - 8 .

Coulter, M. (2003). Entrepreneurship in action, $2^{\text {nd }}$ edition. New Jersey: Prentice Hall.

Devey, R., Skinner, C. \& Valodia, I. (2003). Informal Economy Employment Data in South Africa: A Critical Analysis. Paper presented at the TIPS AND DPRU FORUM 2003, The Challenge of Growth and Poverty: The South African Economy since Democracy, 8 - 10 September 2003, Indaba Hotel, Johannesburg.

Gartner, W.B. (1988). "Who is an Entrepreneur?" Is the Wrong Question. American Journal of Small Business, 12(4), 11 - 32.

Gonzo, W. \& Plattner, I.E. (2003). Unemployment in an African country: a psychological perspective. Windhoek: University of Namibia Press.

Hofmeyr, J.F. (1998). Segmentation in the South African labour market. Potchefstroom: South African Network for Economic Research, working paper no. 15.
Kiggundu, M.N. (2002). Entrepreneurs and Entrepreneurship in Africa: What is Known and What Needs to be Done. Journal of Developmental Entrepreneurship, 7 (3), 239 - 258.

Kuratko, D.F. (2006). A Tribute to 50 Years of Excellence in Entrepreneurship and Small Business. Journal of Small Business Management. Milwaukee, 44 (3), 483 - 492.

Kuznetsov, A., McDonald, F. \& Kuznetsova, O. (2000). Entrepreneurial qualities: A case from Russia. Journal of Small Business Management. Milwaukee, 38 (1), 101 - 107.

Ligthelm, A.A. (2004). Informal markets in Tshwane: Entrepreneurial incubators or survivalist reservoirs? Bureau of Market Research, UNISA. Report number 335.

Ligthelm, A.A. (2006). Size estimate of the informal sector in South Africa. Southern African Business Review, 10 (2), $32-52$.

Loots, A.E. (1998). Job creation and economic growth. The South African Journal of Economics, 66 (3), 319 - 336.

Martins, J.H. (2004). Minimum and supplemented living levels in the main and other selected urban areas of the RSA, March 2004. Bureau of Market Research, UNISA. Report number 334

Muller, C. (2003). Investigating South Africa's Informal Sector: Measurement, Participation, and Earnings. Unpublished master's thesis, University of Natal, Durban.

Schenck, R. \& Louw, H. (2005). An exploratory study on day labourers in Elardus Park Pretoria. Social Work/Maatskaplike Werk, 41 (1), 84 - 95.

Statistics South Africa. (2003). Labour Force Survey, September 2002. Pretoria.

Timmons, J.A. (1994). New venture creation: Entrepreneurship in the $21^{\text {st }}$ century, $4^{\text {th }}$ edition. Chicago: Irwin.

United Nations Development Programme (UNDP). (2003). South Africa Human Development Report 2003-Summary. Cape Town: Oxford University Press.

Valenzuela Jr., A., Theodore, N., Meléndez, E. \& Gonzalez, A.L. (2006). On the corner: Day labour in the United States. UCLA.

Valodia, I., Lebani, L., Skinner, C. \& Devey, R. (2006). Low-waged and informal employment in South Africa. Transformation 60 (2006), ISSN 0258-7696, 90 - 126.

Van Aardt, I. \& Van Aardt, C. (1997). Entrepreneurship and new venture management, $1^{\text {st }}$ edition. Halfway House: International Thompson Publishing (Southern Africa).

Van Wyk, R., Boshoff, A.B. \& Bester, C.L. (2003). Entrepreneurial Attitudes: What are Their Sources? South African Journal of Economic and Management Sciences NS 6 (1), 1 - 24.

Whiteford, A. \& Van Seventer, D.E. (1999). Winners and Losers: South Africa's changing income distribution in the 1990s. Menlo Park: WEFA Southern Africa. 
REVIEW PANEL EDITION 5.1 (2007)

Prof HE Brandt

Dr M Coetzee

Ms S Goosen (Industrial Psychologist)

Prof JJ Havenga

Dr K Janse Van Rensburg

Prof W Jordaan

Prof M Kotze

Prof RG Le Roux

Prof C MacDonald

Dr P Nel

Ms A Odendaal (Industrial Psychologist)

Ms C O’Neil (Industrial Psychologist)

Prof HJ Pietersen

Prod M Sutherland

Dr L de Swart

Dr C Tustin

Dr R van Niekerk

Ms J White (Industrial Psychologist)
University of Pretoria

University of South Africa (UNISA)

Rhodes University

North West University (Potchefstroom Campus)

Spoornet

Professor Emeritus

University of the Free State

University of KwaZulu Natal

University of the Witwatersrand (WITS)

University of Stellenbosch

University of Johannesburg

University of KwaZulu Natal

University of Limpopo

GIBS

ABSA

University of Otago, New Zealand

Rhodes University

Private Consultant 